\title{
Análisis de las dificultades de los estudiantes angloparlantes con el aprendizaje del español en Jamaica ${ }^{1}$
}

\section{Analysis of the difficulties of English-speaking students with learning Spanish in Jam ica}

Recibido: 12 de octubre de 2016- Revisado: 26 de enero de 2017 - Aceptado: 10 de abril de 2017.

\section{Licenia Yaneth Perea Santos ${ }^{2}$}

Edison Valencia Mosquera ${ }^{3}$

\section{Resumen}

El presente artículo surge de un trabajo investigativo cuyo ‘ jetivo fue describi cuáles son las mayores dificultades que enfrentan los estudiantes al 'oparlantes amaicanos en el aprendizaje del español e identificar y analizar rué tipo de "ores so. más comunes entre estudiantes orientados con docentes nativos y 's. 'iantes con pruiesores no nativos, así mismo, identificar los errores que tienden a fosı izars, n más facilidad entre estos aprendices angloparlantes jamaicanos $c_{2}$ puede $c$.cluir $r_{\mathfrak{s}}$ e los errores cometidos por estudiantes orientados por do entes ativos y no nativos señalan la presencia indiscriminada de errores fosilizado tada a fuerza de a interferencia de la L1, el inglés, común a ambos grupos de es ${ }^{+}$ddiantes.

\section{Palabras clave}

Español, errores, fr silización, ì rlingua, aprendizaje, enseñanza, lingüístico, etiológico, pedagógico.

\begin{abstract}
The $r . t$ article rises $f . \mathrm{m}$ a research work whose main objective was to describe, th ugh th analysis -rrors, the main difficulties faced by English-speaking Jamaican stuc. ts $i$ 1aarning Spanish, identifying and analyze what type of errors are most common amon $_{\varepsilon}$ tudents $v_{1}$ a native teacher of Spanish and those of non-native teacher, as well as identify. the errors that tendency is to fossilize in an easier way among these Jamaican English-st, eaking learners. The mistakes made by the students in both teachers, indicate the indiscriminate presence of fossilized errors, given the strength of the interference of the L1, English, common to both groups of students.
\end{abstract}

\section{Keywords}

Spanish, errors, fossilization, interlingua, learning, teaching, linguistic, etiological, pedagogical.

\footnotetext{
1 Este artículo se deriva de la tesis "Aspectos de la enseñanza y el aprendizaje de la lengua española en Jamaica. Análisis de errores en estudiantes jamaicanos del español como segunda lengua".

2 Doctora en Cuestiones de Lengua Sociolingüística y Crítica Textual Española En su Contexto Histórico y Filológico. Docente en la Corporación Universitaria Adventista, Medellín, Colombia. Correo electrónico: yperea @unac.edu.co.

${ }^{3}$ Magister en Piano. Docente en la Corporación Universitaria Adventista, Medellín, Colombia. Correo electrónico: evalencia@unac.edu.co

Para citar este artículo use: Perea, L., y Valencia, E. (2018). Análisis de las dificultades de los estudiantes angloparlantes con el aprendizaje de español en Jamaica. Revista Civilizar, 18(34), 189-200.
} 